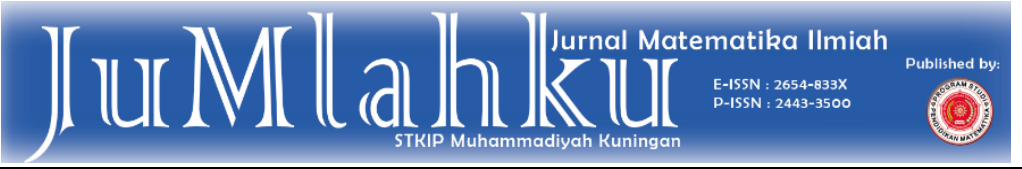

Submited: 2020-10-22

Published: 2020-12-04

\title{
Pengaruh Strategi Konflik Kognitif Terhadap Kemampuan Pemahaman Matematis Taruna Teknika Akademi Maritim Cirebon
}

\author{
Handayani Eka Putria), Yosi Adiputrab) \\ a,b) Akademi Maritim Cirebon \\ handayaniekaputri1990@gmail.com ${ }^{\text {a) }}$,yosiadiputra@gmail.com ${ }^{\text {b) }}$
}

\begin{tabular}{ll}
\hline \multicolumn{1}{c}{ Article Info } & \multicolumn{1}{c}{ Abstract } \\
\cline { 1 - 1 } $\begin{array}{l}\text { Kaywords : Cognitive } \\
\text { Conflict, Mathematical }\end{array}$ & $\begin{array}{l}\text { This research aims to determine the effect of using cognitive conflict } \\
\text { Understanding, }\end{array}$ \\
Nonequivalent & Cirebon Maritime Academy. The design used in this research is \\
Postest Control Group & research were all students at the first level of the Cirebon Maritime \\
Design & Academy for the Academic Year 2020/2021. Sample of this research \\
& are two classes of Teknika Students at Cirebon Maritime Academy. \\
& This research consist of two groups. Learning using cognitive conflict \\
& strategy group and conventional learning group. Data of this \\
& research were collected through tests of mathematical understanding \\
& ability. The Data were analyzed by using the nonparametric Mann \\
& Whitney test. The result of this study is the average of mathematical \\
understanding ability from students using cognitive conflict strategy \\
is higher than the average of mathematical understanding ability from \\
students using conventional methods.
\end{tabular}


Kata Kunci: Konflik

Kognitif, Pemahaman

Matematis,

Nonequivalent

Postest Control Group

Design

\section{Abstrak}

Penelitian ini bertujuan untuk mengetahui pengaruh penggunaan strategi konflik kognitif terhadap kemampuan pemahaman matematis taruna Akademi Maritim Cirebon. Desain yang digunakan dalam penelitian ini adalah Nonequivalent Postest Control Group Design. Populasi dalam penelitian ini adalah seluruh taruna tingkat I Akademi Maritim Cirebon Tahun Akademik 2020/2021. Sedangkan sampel penelitiannya adalah taruna Teknika tingkat I Akademi Maritim Cirebon sebanyak dua kelas. Kelas eksperimen adalah kelas yang mendapatkan perlakuan perkuliahan dengan menggunakan strategi Konflik Kognitif. Kelas kontrol adalah kelas yang mendapatkan perlakuan perkuliahan matematika konvensional. Data penelitian dikumpulkan melalui tes kemampuan pemahaman matematis. Analisis data dilakukan dengan menggunakan uji nonparametrik Mann Whitney. Kesimpulan dari penelitian ini adalah Rata-rata kemampuan pemahaman matematis taruna yang menggunakan strategi konflik kognitif lebih tinggi dari rata-rata kemampuan pemahaman matematis taruna yang menggunakan metode konvensional. 


\section{PENDAHULUAN}

Saat proses pembelajaran matematika berlangsung, sebenarnya seseorang tidak hanya dituntut untuk mendapatkan informasi serta menghapal berbagai aturan-aturan, rumus-rumus, definisi-definisi serta berbagai macam prosedural dalam matematika. Namun keaktifan dalam proses pembelajaran juga sangat diperlukan, sehingga pengetahuan matematika dapat dipahami dengan baik. $\mathrm{Hal}$ ini sejalan dengan pendekatan kontruktivisme yang dinyatakan oleh Yuliati (Suhandri, 2016) bahwa Pengetahuan dikonstruksi secara unik oleh setiap siswa. Siswa akan secara aktif mengkonstruksi pengetahuan untuk memahami konsep, menginterpretasikan informasi baru dalam struktur kognitifnya.

Alam (2012) mengemukakan bahwa seseorang yang memiliki pemahaman konsep matematika yang baik akan mengetahui lebih dalam tentang ideide matematika, dia dapat memberikan pendapatnya, menjelaskan suatu konsep, serta memiliki dasar dalam pembentukan pengetahuan baru sehingga dapat digunakan dalam memecahkan masalahmasalah baru .Oleh karena itu kemampuan pemahaman matematis merupakan kemampuan yang penting untuk dimiliki.

Hal ini sejalan dengan pendapat Turmudi (2009) menyatakan siswa harus belajar matematika dengan pemahaman, membangun pengetahuan baru secara aktif dari pengalaman dan pengetahuan yang dimiliki siswa sebelumnya. Belajar Matematika dengan pemahaman akan menjadikan siswa mampu menerapkan prosedur, konsep-konsep, dan proses matematika.
Berdasarkan pengalaman peneliti pada saat perkuliahan, penggunaan metode perkuliahan pada umumnya dirasa belum dapat memicu mahasiswa untuk mengkonstruksi sendiri pengetahuannya terhadap materi yang diberikan. Menurut teori kontruktivisme yang diungkapkan Piaget (Cole dan Wertsch, 1996) bahwa pengetahuan yang dimiliki seseorang merupakan pengetahuan hasil kontruksi yang dilakukan sendiri. Jika seseorang belum bisa mengkontruksi pengetahuannya, hal ini mengakibatkan adanya jalan buntu untuk mendapatkan pengetahuan berikutnya. Oleh karena itu dibutuhkan suatu model/metode/strategi yang dapat menjadi trigger untuk mengkontruksi pengetahuan sehingga dapat meningkatkan kemampuan kognitifnya.

Strategi konflik kognitif merupakan strategi pembelajaran yang berdasarkan pada pendekatan kontruktivisme. Lee dan Kwon (Lee, dkk., 2003) menyebutkan bahwa konflik kognitif adalah keadaan persepsi disaat seseorang menyadari perbedaan antara struktur kognitif dengan lingkungannya (informasi eksternal), atau antara komponen-komponen yang berbeda (misalnya, konsepsi, keyakinan, substruktur dan sebagainya) dari struktur kognitif seseorang. Menurut teori Piaget (Lee,dkk., 2003), ketika seseorang mengakui konflik kognitif (disequilibrium), pengakuan ini memotivasi dia untuk mencoba menyelesaikan konflik. Piaget menyebut proses penyelesaian konflik ini adalah "equilibrium". Menurutnya, equilibrium mengacu pada proses pengaturan diri yang memelihara 
keseimbangan antara asimilasi dan akomodasi.

Sejak 1980-an menurut Lee, dkk.(2003) penggunaan konflik kognitif sebagai strategi pengajaran telah populer di bidang pendidikan sains dan sejumlah besar peneliti berpendapat bahwa konflik kognitif memiliki peran penting dalam perubahan konseptual, artinya strategi konflik kognitif mampu untuk membentuk pemahaman konsep

Ismaimuza (2008) menyatakan bahwa konflik kognitif adalah keadaan dimana terdapat ketidak cocokan antara struktur kognitif (skemata) yang dimiliki atau dipunyai oleh seseorang dengan informasi yang baru dia dapat dari luar, jadi informasi baru yang diterimanya tidak cocok dengan struktur kognitif yang telah dia miliki.

$\begin{array}{lcc}\text { Sayce dalam bukunya } & \text { (2009) } \\ \text { menjelaskan } & \text { susunan dalam } \\ \text { merencanakan } & \text { pembelajaran }\end{array}$
menggunakan strategi konflik kognitif, yaitu (1) Expected cognitive conflict : pengajar memprediksi isu utama yang memungkinkan akan menimbulkan konflik kognitif, (2) Prior learning needed : pengajar mencari informasi mengenai pengetahuan apa yang telah peserta didik miliki sebelumnya. (3) Comfort zone : dalam tahapan belajar awal, menetapkan zona kenyamanan, pengajar perlu memulai dengan suatu permasalahan yang sederhana sehingga semua peserta didik akan mudah memahaminya, (4) Exploration : pada tahap ini peserta didik bisa jatuh dalam zona aman awalnya, tapi itu perlu agar peserta didik memiliki waktu untuk eksplorasi dan eksperimentasi agar mereka diharapkan nantinya menemukan situasi yang menyebabkan konflik kognitif, (5) Trigger : pengajar memberikan pemicu berupa suatu permasalahan yang mendorong peserta didik untuk berpikir di luar dari zona kenyamanan mereka (konflik kognitif), (6) What next : konflik kognitif ini mungkin memberikan titik awal untuk mempelajari pengetahuan baru.

\section{METODE}

Pada penelitian ini terdapat dua kelompok mahasiswa yang mendapat perlakuan berbeda, yaitu kelompok ekpserimen atau disebut kelas eksperimen dan kelompok kontrol atau disebut kelas kontrol. Kelas eksperimen diberikan perlakuan strategi konflik kognitif sedangkan kelas kontrol diberikan perlakuan model perkuliahan seperti pada umumnya. Setelah perlakuan selesai dilakukan, kedua kelas diberikan tes kemampuan pemahaman matematis untuk mengetahui manakah yang lebih tinggi antara kemampuan pemahaman matematis yang terjadi setelah diberikan kedua perlakuan yang berbeda.

Penelitian ini menggunakan desain Control Group Post test only design (Ruseffendi, 2005) dengan pola sebagai berikut:

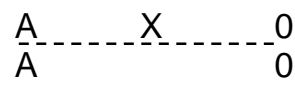

Keterangan
A : Pengambilan sampel secara acak menurut kelas
$\mathrm{X}$ : Kelompok yang memperoleh strategi konflik kognitif
0 : post-test 
Populasi dalam penelitian ini adalah seluruh mahasiswa/taruna jurusan Teknika Akademi Maritim Cirebon, sedangkan sampelnya diambil 2 kelas. Perolehan data dalam penelitian ini menggunakan instrumen tes kemampuan pemahaman matematis berupa seperangkat soal untuk mengukur kemampuan pemahaman matematis nahasiswa.

Tes kemampuan pemahaman matematis yang digunakan pada penelitian ini berbentuk tes uraian. Tes ini bertujuan untuk mengetahui kemampuan pemahaman matematis mahasiswa pada kelas eksperimen dan kontrol. Sebelum soal tes pemahaman matematis digunakan, terlebih dahulu diujikan di luar sampel dengan tujuan mencari validitas dan reliabilitas tes.

Indikator kemampuan pemahaman yang termuat pada butir soal dalam penelitian ini adalah 1) Pemahaman instrumental : Menghapal rumus/prinsip, dapat menerapkan rumus dalam perhitungan sederhana dan mengerjakan pehitungan secara algoritmik, serta 2) Pemahaman relasional : Mengaitkan sesuatu dengan hal lainnya secara benar serta menyadari prosesnya.

\section{HASIL DAN PEMBAHASAN}

Penelitian diawali dengan pembuatan instrumen pemahaman matematis, kemudian instrumen yang telah dibuat diujikan kepada mahasiswa tingkat 2 untuk diteliti validitas dan reliabilitasnya. Dari hasil uji validitas dan reliabilitas, diperoleh hasil bahwa nilai koefisien validitas untuk keempat butir soal termasuk kategori tinggi, begitu pula dengan 192 koefisien reliabilitasnya termasuk tinggi. Jadi, soal instrumen pemahaman masalah matematis dapat digunakan. Selain itu peneliti juga membuat perangkat penelitian yang terdiri dari silabus, lembar kerja, soalsoal tes dan tugas individu.

Setelah pemberian perlakuan strategi konflik kognitif pada kelas eksperimen, serta perkuliahan secara konvensional pada kelas kontrol, dilakukan tes guna mengetahui mana yang lebih baik kemampuan pemahaman matematisnya antara kelas eksperimen dengan kelas kontrol. Dari hasil tes yang telah dilakukan, diperoleh hasil sebagai berikut :

Gambar 1

\section{Statistik Deskriptif Hasil Test Kelas Eksperimen dan Kontrol}

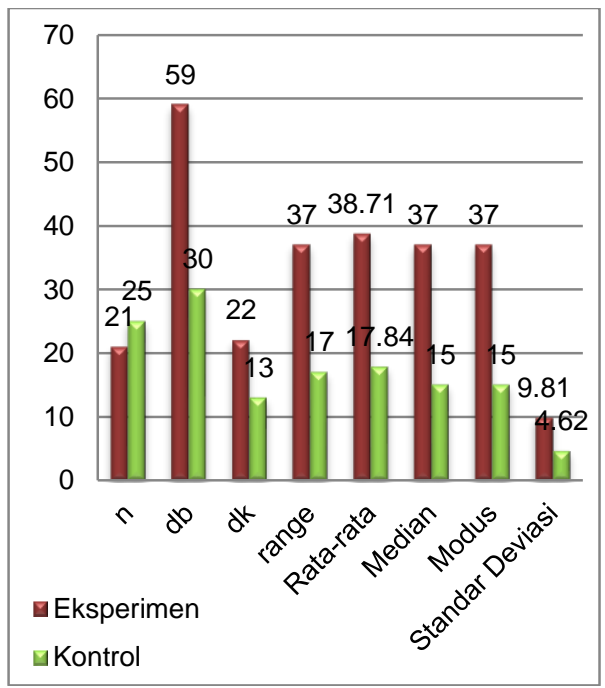


Berdasarkan gambar 1, diperoleh informasi bahwa skor tertinggi tes pemahaman matematis pada kelas eksperimen adalah 59 dari skor maksimum 80. Sedangkan untuk skor terendah adalah 22. Adapun untuk kelas kontrol, skor tertinggi tes pemahaman matematis adalah 30, dan skor terendahnya adalah 13. Sedangkan nilai rata-rata untuk kelas eksperimen sebesar 38,71 dan rata-rata untuk kelas kontrol sebesar 17,84. Disini bisa kita lihat bahwa rata-rata kelas eksperimen lebih baik daripada kelas kontrol. Namun itu belum cukup untuk dijadikan alasan pengambilan kesimpulan. Oleh karena itu akan dilakukan diuji perbedaan 2 rata-rata, namun sebelumnya akan dilakukan uji normalitas terlebih dahulu.

\begin{tabular}{l} 
Tabel 1 \\
\multicolumn{3}{c|}{ Hasil Uji Normalitas } \\
\begin{tabular}{|l|l|l|l|l|}
\hline \multirow{2}{*}{ Kelas } & Kolmogorov-Smirnov & $\begin{array}{l}\text { Kesim } \\
\text { pulan }\end{array}$ \\
\cline { 2 - 4 } & $\begin{array}{l}\text { Statisti } \\
\text { c }\end{array}$ & df & Sig. & $\begin{array}{l}\mathrm{H}_{0} \\
\text { ditolak }\end{array}$ \\
\hline $\begin{array}{l}\text { Eksperim } \\
\text { en }\end{array}$ & 0,193 & 21 & 0,041 & $\begin{array}{l}\mathrm{H}_{0} \\
\text { ditolak }\end{array}$ \\
\hline Kontrol & 0,266 & 25 & 0,000 \\
\hline
\end{tabular}
\end{tabular}

Dari hasil pengolahan data di atas,
terlihat bahwa nilai signifikansi uji
Kolmogorov-Smirnov untuk kelas
eksperimen sebesar 0,041 dan kelas
kontrol sebesar 0,000 . Karena nilai Sig $<$ a
$(0,05)$, maka dapat disimpulkan bahwa
data hasil tes tidak berdistribusi normal.
Oleh karena itu uji perbedaan dua rata-rata
akan menggunakan uji statistik non
parametrik yaitu uji Mann Whitney $U$.

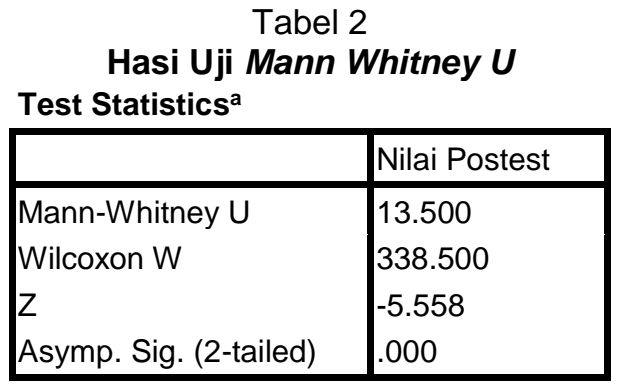

a. Grouping Variable: Kelas

Dari hasil uji Mann Whitney pada tabel di atas, diperoleh nilai sig (2-tailed) sebesar 0,000. Maka, nilai sig (1-tailded) sebesar 0,000/2 yaitu 0,000. Karena nilai sig (1-tailed) kurang dari 0,05 maka hipotesis nol ditolak, kesimpulannya ratarata kemampuan pemahaman matematis taruna yang menggunakan strategi konflik kognitif lebih tinggi dari rata-rata kemampuan pemahaman matematis taruna yang menggunakan metode konvensional. Hasil ini didukung oleh pendapat Ismaumuza, (2013) bahwa pembelajaran dengan strategi konflik kognitif mampu mendorong pelajar memahami, membina pengetahuannya sendiri sehingga mampu mengusai suatu konsep. Oleh karena itu, taruna yang mendapatkan pembelajaran dengan menggunakan strategi konflik kognitif memiliki rata-rata kemampuan pemahaman yg lebih tinggi dibandingkan rata-rata kemampuan pemahaman taruna yang mendapatkan pembelajaran dengan menggunakan metode konvensional.

\section{KESIMPULAN DAN SARAN}

1. Rata-rata kemampuan pemahaman matematis taruna yang menggunakan strategi konflik kognitif lebih tinggi dari 
rata-rata kemampuan pemahaman matematis taruna yang menggunakan metode konvensional.

2. Penggunaan strategi konflik kognitif dalam pembelajaran kiranya perlu memperhatikan faktor-faktor yang mungkin bepengaruh terhadap konflik kognitif yang terjadi. Faktor-faktor tersebut meliputi faktor yang berhubungan dengan mahasiswa, dosen dan lingkungan tempat pembelajaran terjadi.

\section{DAFTAR PUSTAKA}

Alam, B. I. (2012). Meningkatkan kemampuan pemahaman dan komunikasi matematika Siswa SD melalui pendekatan realistic mathematics education (RME). Prosiding Seminar Nasional Matematika dan Pendidikan Matematika. Yogyakarta, Universitas Negeri Yogyakarta, hlm.150-164.

Cole, M., \& Wertsch, J. (1996). Beyond the individual-social antimony in discussions of Piaget and Vygotsky. Human Development, hlm.250-256.

Ismaimuza, D. (2008). Pembelajaran Matematika Dengan Konflik Kognitif. Seminar Nasional Matematika dan Pendidikan Matematika. 155-166.

, D. (2013). Kemampuan Berpikir Kritis dan Kreatif Matematis Siswa SMP Melalui Pembelajaran Berbasis Masalah dengan Strategi Konflik Kognitif. Jurnal Teknologi
(Sciences \& Engineering) 63:2 (2013), 33-37.

Lee, G. dkk. (2003). Development of an instrument for measuring cognitive conflict in Secondary-Level Science Classes. Journal of Research in Science Teaching, 40 (6), hlm. 585-603.

Ruseffendi, E. T. (2005). Dasar-dasar penelitian pendidikan dan bidang non-eksakta lainnya. Bandung: Tarsito.

Sayce, Lucy. (2009). The route to cognitive conflict. National Centre for Excellence in The Teaching of Mathematics.

Siegel, S. 1986. Statistik Non-Parametrik Untuk Ilmu-ilmu Sosial. Jakarta : Gramedia

Suhandri, (2016). Meningkatkan Kemampuan Pemahaman Matematis Siswa SMP/MTs Dengan Menggunakan Strategi Konflik Kognitif. JPPM, 9 (2), hlm 240-249

Turmudi (2009). Taktik dan Strategi Pembelajaran Matematika. Jakarta : Leuser Cita Pustaka. 